East African Journal of Science, Technology and Innovation, Vol. 2 (1): December 2020.

This article is licensed under a Creative Commons license, Attribution 4.0 International (CC BY 4.0)

\title{
The Internet in East Africa: a mixed methods study
}

\author{
${ }^{1 *}{ }^{\prime}$ BRIAIN D., ${ }^{1 D E N I E F F E ~ D ., ~}{ }^{2}$ OKELLO D., 1 KAVANAGH Y
}

\author{
${ }^{1}$ Department of Aerospace, Mechanical and Electronics, Faculty of Engineering, Institute of Technology Carlow, \\ Kilkenny Road, Carlow, Ireland R93 V960 \\ ${ }^{2}$ School of Engineering, College of Engineering, Design, Art \& Technology, Makerere University, P.O. Box 7062, Kampala, \\ Uganda. \\ *Corresponding author: Diarmuid.OBriain@itcarlow.ie
}

\begin{abstract}
East Africa was the last major area of the world to gain access to the Internet when submarine fibreoptic cables landed at Mombasa, Kenya and Dar-es-Salaam, Tanzania in 2009. The region previously relied on satellite communications to individual Internet Service Providers (ISP). This presented a unique opportunity to acquire and document the thoughts of key business, political and technical leaders who were, and continue to be, an integral part of the development of the regional Internet ecosystem from 2009, via the SEACOM and TEAMS cables. This prompted a mixed methods political economy study of the Internet in East Africa to gain an understanding of why the regional Internet infrastructure developed as it did, a vision of the future direction of the regional Internet, a view of the disruptive potential of new networking technologies such as Software Defined Networking (SDN) and Network Functions Virtualisation (NFV) as well as the growth of the Internet's multinational online companies that now dominate the Internet. The study concludes that the landing of the submarine fibre-optic cables was the catalyst for improvements that drove the development of regional infrastructure leading to rapidly improving Internet services such as streaming video facilitated by investment in ISP and Internet eXchange Points (IXP) improvements through mobile phone generations and roll-outs across the region have facilitated citizen access. The study also shows that fibre will play an increasingly important role; however, wireless that will remain the key delivery Internet platform over the next decade.
\end{abstract}

Keywords: content; exchange; fibre-optic; Internet.

\section{Introduction}

East Africa was the last major region of the world to be connected to the Internet via submarine fibre-optic cable (Graham et al., 2015). At that time, less than a decade ago, the region did not have a developed cross-border terrestrial fibre-optic cable network. Internet access transit consisted of direct satellite Internet connections at each ISP and Mobile Network Operators (MNO).

There has been rapid development of the regional Internet infrastructure over the decade. This study, with a particular focus on Kenya, Rwanda, Tanzania and Uganda, considers the factors that were involved to bring the regional Internet to its current state as well as form predictions as to the possible future direction it will take over the next decade.

\section{Study Objectives}

The objectives of the study were: to determine how the Internet evolved in East Africa from when the submarine fibre-optic cables landed at the coast. To posit a view of how the Internet will evolve in East Africa over the next decade.
Cite as: O'Briain et al., 2020. The Internet in East Africa, a mixed methods study East African Journal of Science, Technology and Innovation 2(1)
Received: $\quad 08 / 07 / 20$

Accepted: $\quad 30 / 08 / 20$

Published: $11 / 12 / 20$ 
The project aimed to determine the state of the Internet in East Africa beyond that which could be obtained by statistical quantitative means. As the time period since the fibre-optic cables landed in the region was within a decade, a qualitative approach, through interviews with subject matter experts that participated in the built and development of the regional Internet, was considered suitable to discover the factors involved that brought the Internet to its current state, and to predict the possible future direction the Internet will take within the region.

\section{Materials and Methods}

The scale of the region as well as the political situation within the constituent countries meant that choices had to be made as to which countries to include. Uganda was selected as the inland country which has a dependency on access to the submarine fibre-optic cables at the coast. Interview participants from both Kenya and Tanzania were included; however, as Ugandan Internet traffic uses Mombasa and Rwandan ISPs generally prefer the Uganda/Kenya route over Dar-es-Salaam, Kenya was prioritised as the main coastal country for the project. The final country selected, due to its unique dependence on multiple countries to reach the submarine fibreoptic cables at the coast, was Rwanda. While it borders Tanzania and has links to Dar-esSalaam, Rwandan providers, in general, choose the longer route through Uganda/Kenya to access submarine fibre-optic cables in Mombasa. For these reasons, the three countries, Kenya, Rwanda and Uganda are the focus of this paper.

Qualitative interviews were carried out with 25 business, political and technical leaders considered to be an expert group in the telecommunication sector in East Africa ('the participants').

The study employed a purposive sampling technique. Employing this technique, the population may not be statistically representative of the overall population because the selected participants are those with many years' experience in the sector and fit the subject matter expert profile required by the study (Flick, 2018).
Interviews were semi-structured in which participants were given open-ended focused questions, from an interview guide, on a series of topics relating to core Internet provision using well defined interview techniques (Edwards \& Holland, 2013) on the 1) state of the Internet today, 2) changing nature of Internet traffic; function and benefits of IXP, 3) future software-defined paradigms, 4) expected evolution of future networks, and 5) Internet ecosystem changes that are necessary in the future.

The study was conducted such that the outputs meet the credible, dependable, confirmable and transferable criteria expected to ensure rigour (Houghton et al., 2013). This was achieved by the researcher visiting each participant at their offices in Dar-es-Salaam, Kampala, Kigali and Nairobi. Consideration was also given to ensure that there was adequate representation from those involved in policy, in this case the multi-lateral and government ministries; those involved in communication regulators, and implementers, namely ISPs, Internet Data Centres (IDC) and IXPs.

Dependability and confirmability criteria of the data from the interviews was established by setting a baseline for each theme and category. To warrant inclusion in the analysis it needed to be agreed by more than one participant and the more participants that made similar points the more dependable the data was considered. However, considering the expert nature of the participants, individual comments were, in some cases, included where they offered rich information and it was possible to corroborate the information. Transferability determines if the findings from the interviews can be transferred to other similar contexts or situations, while still preserving the meanings and inferences (Leininger, 1994). The information was categorised, ordered with detailed descriptions provided for each theme and category such that a reader considering another context or situation can determine the transferability of each point.

The outputs were also corroborated using across-method methodological triangulation via an Internet survey of engineers and academics who also work in the sector delivering the Internet across Africa ('the 
respondents'). The survey form was distributed electronically to the African Network Operators Group (AfNOG), made available in hardcopy at the Information Society and Technology (IST) Africa (ISTA) 2018 conference in Gaborone, Botswana from the 9-11 May 2018 and at the African Peering and Internet Forum (AfPIF) 2018 conference in Cape Town, South Africa from the 21-23 August 2018. Respondent numbers in each group are within statistical norms for a small survey when Hoyle's Finite Population Correction Factor (FPCF) (Hoyle, 2018) is applied to the ideal sample size (Krejcie \& Morgan, 1970).

An anonymised version of the dataset was used for analysis and each question was assessed for statistical significance between the three groups using Pearson's $X^{2}$ test of homogeneity.

The purpose of carrying out both was to apply across-method triangulation (Boyd, 1993), to ensure completeness of the dataset and to reach data saturation (Fusch \& Ness, 2015). Similarities, as well as, variances in thinking were identified between the interview participants and the Internet survey respondents.

\section{Results}

\section{The evolution of the Internet in East Africa since 2009}

All participants were clear that the Internet and Information and Communications Technology (ICT) in general has been transformed, in East Africa, over the last decade, a transformation that evolved from the landing of submarine fibre-optic cables in Mombasa and Dar-esSalaam, distributed through new infrastructure and amplified through the interposition of new technologies.

\section{Submarine-fibre Optic cables land in East Africa}

Participants pointed to the landing of the submarine fibre-optic cables connecting East Africa to the Middle East and Europe as the transformational trigger which moved the region from a satellite-based Internet to a rapidly developing terrestrial fibre-optic network interconnecting the region and connecting it to the submarine fibre-optic cables at the coast. As a result, the volume of data that can be processed from the region without adding more fibre-optic cables exceeds $20 \mathrm{~Tb} / \mathrm{s}$.

The advent of the fibre-optic cables coming through Mombasa to Uganda as well and coming inland transformed the Internet space. ("George", Director at an Internet related organisation)

It has become like electricity, it's a medium that's happening in the background without having you pay attention to the fact that yes, that's happening because of that connectivity or that linked up because of the Internet. ("Ambrose", Senior government official)

The survey respondents were asked two related questions to accurately elicit their thoughts on how the Internet is delivered across the region today. The first, a likert question, asking for their opinion as to the state of the Internet in the region over the last 10 years, demonstrated strong evidence of homogeneity between all three groups. 52\%-68\% of all three groups selected very improved and between $32 \%-43 \%$ selected slightly improved, therefore all respondents considered that the regional Internet improved over the past decade.

Statistical evidence of homogeneity was not evident when the survey respondents considered the key catalysts for change; however, Submarine cables landing in Africa and Mobile Network Operators (MNO) rated highly for each group. $48 \%$ of the ISTA group chose MNOs as the key catalyst with Submarine cables landing in Africa their strong second choice at $43 \% .46 \%$ of the AfPIF and $67 \%$ of the AfNOG groups selected Submarine cables landing in Africa as their key catalyst while $14 \%$ and $26 \%$ selected MNOs respectfully; however, the AfPIF second choice, at $18 \%$, was National terrestrial fibre networks. A possible reason for this small discrepancy between the groups could be the fact that $88 \%$ of the AfNOG group are from East Africa which was only connected to the submarine fibre within the last decade it is not surprising therefore that the effect of Submarine cables landing in Africa rated so highly. 


\section{Internet eXchange Points}

IXPs facilitate ISPs, MNOs and Internet Content Providers (ICP) to interconnect locally which has a positive effect on performance indicators such as latency, hop count, packet loss and jitter. They also reduce the number of external transit ISPs traversed by the traffic between the subscribers located on member networks (Muttitanon \& Samanchuen, 2020). North American IXPs are largely for profit with a focus on revenue generation while European IXPs retain a focus on mutual value through cost sharing between a community of members (Norton, 2014).

The scale of African IXPs is much smaller than in North America or Europe, with the notable exception of South Africa. The Uganda Internet eXchange Point (UIXP) is one of East Africa's larger IXPs handling $8 \mathrm{~Gb} / \mathrm{s}$ (UIXP, 1 July 2020). Its 26 members serve a country of 40 million people. Comparing it to Latin America, another developing region, Costa Rica and Panama have populations under 5 million people each, yet both of their IXPs have similar membership numbers to UIXP and carry traffic levels that match or exceed it (Euro-IX, n.d.).

It should be noted that the impact of the recent global Covid-19 pandemic has had differing impacts in different regions. The Irish IXP (INEX), for example, saw traffic levels soar in March to over $500 \mathrm{~Gb} / \mathrm{s}$ (INEX, 1 July 2020) as the economy switched to home working and that level remained even after the lifting of lockdown as workers remained working from home. In Uganda, UIXP traffic had reached over $8 \mathrm{~Gb} / \mathrm{s}$ in February 2020; however, in March it stalled and retracted back to $6 \mathrm{~Gb} / \mathrm{s}$ as Kampala based employees returned to their home villages or were forced to work from home on mobile broadband networks (UIXP, 1 July 2020). Traffic levels rose again in June as the lockdown eased and workers returned to their offices (INEX, n.d.) (UIXP, n.d.).

The open co-operative nature of the European model with a focus on mutual value, the sharing of costs and community oversight offer a convenient place for ICPs to locate their CDNs, as well as neutral location for local content. This presents a more attractive model in East Africa than the commercial profit oriented North American model (Chatzis et al., 2013). The European Internet Exchange
Association (Euro-IX) has also proved very supportive to African IXPs, evidenced by their continued support of the African Peering and Internet Forum (AfPIF).

The role of the IXP is to make the enduser experience a better experience, because if they can access content faster, then they consume more, this means more revenue for the ISPs, because the ISPs must sell bigger pipes. ("Robert", Principal Engineer at an ISP)

There was general consensus from participants that IXPs have been a key part of the Internet ecosystem since the mid-1990s. IXPs originally formed to allow neighbouring ISPs to pass traffic between themselves, for mutual benefit, instead of unnecessarily passing their traffic over Internet transit adding to cost and latency. The IXP has also become a point of data exchange between ISPs, MNOs and ICP typically at IDCs. IXPs remain an important cog in the ecosystem, keeping data local and addressing hairpinning of data over transit.
Before we had IXP connections I saw huge amounts of traffic going from one local network to another local network, going all the way out to the Internet and all the way back in again. Ridiculous situations. ("Doreen", Chief Technical Officer (CTO) at an ISP)

Active participation and strategic routing policies allow members to avoid significant Internet transit, as well as the problems associated with traffic hairpinning via the Middle East, Europe and even the US. IXPs in East Africa have developed significantly from very low traffic volumes in 2001 to traffic levels today measured in $\mathrm{Gb} / \mathrm{s}$, for example Uganda IXP (UIXP) regularly handles in excess of 8 $\mathrm{Gb} / \mathrm{s}$.

There were only $160 \mathrm{Mb} / \mathrm{s}$ in traffic going through eXchange Points across all of Africa. ("Assumpta", $\mathrm{CEO}$ at an ISP)

Some participants revealed that the Kenyan IXP (KIXP) initially came online at the end of 2001 but after two weeks the Communications Authority of Kenya confiscated the equipment while acting on a complaint from the then incumbent operator Telecom Kenya. They 
claimed the IXP was illegal and only the national incumbent could provide an exchange under Kenyan law.

In February 2002 there was an agreement, and a license was issued to the IXP and we went in and switched it on. It was actually Valentine's day of 2002. ("Anne", Director at an Internet related organisation)

Having started with $400 \mathrm{Mb} / \mathrm{s}$ of traffic, KIXP grew, in 2010 it passed the $1 \mathrm{~Gb} / \mathrm{s}$ mark for the first time. Today Technology Service Providers of Kenya (TESPOK) maintains two IXPs, KIXP at the African DataCentres (ADC) Nairobi and the Mombasa IXP (MSIXP) at the Telephone House Data Centre (THDC). KIXP regularly exchanges over $14 \mathrm{~Gb} / \mathrm{s}$ of traffic today (KIXP, 1 July 2020).

In 2010 within a period of seven months KIXP grew traffic exchanged from $400 \mathrm{Mb} / \mathrm{s}$ to $1 \mathrm{~Gb} / \mathrm{s}$ of traffic. ("Robert", Principal Engineer at an ISP)

Both Kenyan IXPs are managed as a neutral, non-profit exchanges without restriction upon the types of organisation or individual who may become members and currently supports peering between ISPs, ICPs, government institutions, banks and other companies.

The eXchange is owned by TESPOK but the mandate is really open to everyone, anybody can be a TESPOK member. What is needed [to join] is an Autonomous System (AS) number $(A S N)$, this makes you a carrier or an ISP in that sense. ("Robert", Principal Engineer at an ISP)

UIXP also started in 2001 and it is the third oldest IXP in Africa. It started with $20 \mathrm{Mb} / \mathrm{s}$ share of the African traffic and today it regularly peaks over $8 \mathrm{~Gb} / \mathrm{s}$. UIXP has 27 connected networks including ICPs such as Google and Akamai, as well as, eGovernment services to each of the ISPs and MNOs in the country.

At UIXP, today we have a lot of diversity, we have 27 networks connected and each one of them, generally speaking, brings something to the table, and some provide more or less value to some of the other networks, there is a little interesting market going on at the eXchange Point. ("Assumpta", CEO at an ISP)

The addition of CDNs by ICPs have been instrumental to IXP development. With each addition there was a noticeable step change in traffic throughput.

In Uganda right now having a cache at the eXchange Point, the networks have a really strong desire to come because the only other way to get that Google content is through the expensive transit upstream. ("Assumpta", CEO at an ISP)

The Rwanda INternet EXchange (RINEX) was founded in 2004, initially located in the IDC of incumbent Rwandatel and ran by volunteers from across the industry. In 2014 RINEX was formalised under the Rwanda Internet Community and Technology Alliance (RICTA), an organisation that was responsible for the country code Top Level Domain (ccTLD) .RW since 2012. RICTA is funded from revenue received from both the .RW domain and RINEX. Traffic volumes between the RINEX 15 peering members is $1.1 \mathrm{~Gb} / \mathrm{s}$ (RINEX, 9 July 2020).

RICTA is a private organisation limited by guarantee paying taxes, staff, etc... Revenue traditionally comes from the domains and since 2014/2015 both the domains and the IXP are generating revenues. ("Ismail", CEO at an ISP)

Once we connected to the eXchange [RINEX] within four months we offloaded roughly $15-20 \%$ of the traffic and now it is moving up. We were able to cut our upstream providers from seven Synchronous Transport Module 1 (STM-1) to just four STM-1s. ("Robert", Principal Engineer at an ISP)

The Tanzania ISP Association (TISPA) formed the Tanzania Internet eXchange (TIX) at Postal House in Dar-es-Salaam in 2003. The government through the Tanzania Communication Regulatory Authority (TCRA), built the National ICT Broadband Backbone (NICTBB), a fibre-optic ring with a goal to 
create a national distributed IXP (dIXP) with exchanges at major cities along its length. TCRA have requested TISPA to migrate TIX in Dar-es-Salaam to the TTCL site.

TIX was established in 2003 by the ISPs themselves through the association TISPA then later on the government through TCRA donated equipment and convinced TISPA to establish regional [local] IXPs, the goal was to, at a later stage to have a ring to connect all these IXPs so that we have a sort of a national IXP connected through the national ICT broadband. ("Gabriel", CTO at an ISP)

There is some imbalance to this dIXP substrate, while there are now five IXPs in Tanzania, only TIX, the original IXP, is viable and regularly handles traffic levels over $9 \mathrm{~Gb} / \mathrm{s}$. The other IXPs at Zanzibar, Arusha, Dodoma and Mwanza have ISPs connected to demonstrate compliance, the level of traffic in each is less than $500 \mathrm{~kb} / \mathrm{s}$. A similar situation has existed in Mombasa where, in 2010, a joint partnership between TESPOK and the Amsterdam IXP (AMS-IX) formed to run MSIXP at the SEACOM landing station in 2010. AMS-IX withdrew from the partnership citing lack of traffic as the reason. TESPOK relaunched MSIXP in THDC 2016.

The first point to be learnt from this is that a business case is necessary before considering the development of additional IXPs. The second point to consider is the direct interconnection of IXPs directly impinges on ISPs who deliver transit services and counteracts initiatives that reduce costs in the transit network. ISPs forced to participate in a national dIXP have no reason to develop competing infrastructure. The result of the Tanzanian dIXP is demonstrated by Rwandan ISPs who choose a route to the submarine fibreoptic cable landing stations in Mombasa via two countries, through Uganda and Kenya, rather than the more direct route to Dar-esSalaam through Tanzania.

Considering the different IXPs there currently is not a link between them, some are quite small, for example in Zanzibar IXP (ZIXP) there are three peers, Arusha City IXP (AIXP) they have 12. Take Dodoma IXP (DIXP) which currently has three members, as government headquarters has moved to Dodoma, the government is pushing to improve it so that more could be connect there but currently there are only three peers. Dar-esSalaam by contrast has 33 peers, Mwanza IXP (MIXP) is the final one and they also have only three peers. Most of the peers in the smaller IXPS are MNOs. They are really not getting any benefit from peering at these sites, they are doing it just to comply with the government because the numbers of peers there are very small, so they are doing it just to comply. In terms of benefit it does not make sense really. ("Gabriel", CTO at an ISP)

Survey respondents were asked questions to understand how they see IXPs within the Internet ecosystem today and their view of them in the future. Strong statistical evidence of homogeneity was evident when they were asked to consider if the IXP have had a positive effect on the Internet in the region over the last 10 years; however, when asked for their opinion on the place of IXPs in the future there was no evidence of homogeneity between groups. A future continuing to act as a point where ISPS and Application Service Providers (ASP) peer and a future to share local content featured high for all three groups. It is possible that some respondents were unclear as to the difference between a future to share local content and a future as a location for $C D N s$ as the latter was rated highly by the AfNOG group. It is surprising that a future as a location for CDNs did not rate more favourably among the respondents from the ISTA and AfPIF groups considering the current trend for CDNs to locate at IXPs.

When the model for IXP management and ownership was analysed, there was strong evidence of homogeneity between the groups. The majority, AfNOG at $74 \%$, AfPIF at $71 \%$ and IST-Africa $48 \%$, consider an organisation/entity of peering members at the IXP as the preferred option and by a local ISP association in second place, in line with the European open, cooperative, cost sharing model. This is not surprising given that the respondents, in general, have industry bias. 
The East African Community (EAC) member states came together as early as 2007 to implement the East Africa IXP (EAIXP), an initiative of the East African Communications Organisation (EACO) Working Group 5 to connect the IXPs of each EAC state into a single regional IXP (EACO, 2012a) (EACO, 2012b) (EACO, 2014).

The idea behind this project [EAIXP] was to have the IXPs in the region interconnect either logically, physically whichever way to trunk and exchange traffic within the region without traversing outside of the East African region. It was to improve the Internet experience of users and to reduce on the costs and latency. The EAIXP project changed to the East Africa Peering and Interconnection project because the experts who were involved in that project thought that connecting IXPs was not viable, but we need to talk of peering and Interconnection in the region. ("Justine", Senior Manager at a Multi-lateral organisation)

Which ISPs would get to carry the traffic between the elements of this regional IXP as the EAIXP would replace some of the function that transit carrying ISPs do today?

Simbanet, who were initially awarded a contract, to make the inter-connections between the IXPs, were unable to implement the project due to several challenges including the reluctance of other ISPs to participate. There were many questions as to the feasibility of the project, despite some noble intentions behind it and this resulted in the concept being transformed into a peering forum to discuss best practice (EACO, 2017).

It is not a case of let's wake up one day and interconnect the IXPs, we need to think about who does it affect and who gains the most from it and what is the current structure. When it comes to East Africa I am not of the view that we should build an East Africa IXP but I am of the view that the different IXPs need to peer each other. ("Denis", Senior government official)

While the EAIXP did not take off, the idea that a country or region will require more than one
IXP in the future was raised by a number of the participants. To develop industry and technology hubs away from the main cities will eventually require the development of multiple IXPs, a dIXP. The reasons for not directly interconnecting national IXPs in the region apply at least equally, if not more so, to a national dIXP.

\section{Content delivery networks}

CDNs are a distributed network of proxy servers, located in IDCs across the globe, to provide high availability and performance through the distribution of web objects and network services as close as possible to end users (Shi et al., 2018). They are the most significant reason for the relatively recent transformation of IXPs as the offer a neutral point for the incorporation of $\mathrm{CDNs}$ in the regional Internet peering ecosystem.

Content trying to come close to the users that makes exchange points basically distribution points for content rather than a more diverse healthy robust ecosystem of varying size networks with different things to offer. A Google can plug into an exchange point as the most efficient way to distribute their content instead of a mesh of interconnected links. ("Assumpta", CEO at an ISP)

What has also helped the IXP to grow is the CDN, because we are getting quite a number of $C D N$ s posted at the exchange now. All of us want access to those CDNs. The fact that we can keep our traffic local and cut down on upstream costs is a good thing. ("Denis", Senior government official)

However, when asked if this is healthy for the local Internet ecosystem, some were noncommittal. It currently suits the ICPs to locate at IXPs, they could alternatively establish private exchanges and force ISPs to come to them for connections. This would create a monopolist situation as their content becomes the exchange driver and not a healthy ecosystem of peers.
In terms of the potential for monopolies on content, that is certainly a problem, any time you 
have a monopoly. It is here already, Facebook doing acquisitions at alarming rates, it is Google doing acquisitions at alarming rates. ("Lena", Director at an Internet related organisation)

When the survey respondents were asked for their opinion on what has had the most significant impact on video services in the region over the last 10 years there was strong statistical evidence of homogeneity between groups as Caching and $C D N s$ received just under half of the first preference selections and had a strong showing among the second and third options of the other respondents. However, the very strong second preference result for ISPs meant it was given almost equal significance with $M N O s$ and IXPs also showing strong support overall. While credit must be given to ISPs and MNOs for making improvements on their networks, the fact that ICPs have located CDNs on both local ISP and IXP networks, bringing their content closer to their customers, is seen as the major contributing impact to video services in the region.

\section{Internet development in East Africa over the next decade}

The second study question contemplated potential future Internet developments in the region through the impact of new disruptive technologies as well as potential developments or repurposing of existing technologies and a potential viewpoint was posited.

\section{Distributed Internet eXchange Points}

It has been witnessed in other jurisdictions that an increase in the number of IXPs helps to increase network speed and reduce costs. IX.br, the Brazilian ecosystem, has grown from four IXPs to 25 in operation and 16 new locations under evaluation using a non-profit business model (Brito et al., 2016). The additional IXPs helped to decrease network latency and bypass international traffic fees (WEF, 2018).

The NAPAfrica Internet eXchanges, located in Teraco IDCs in Cape Town, Durban and Johannesburg come under single management and offer an African example (McCann, 2018). However, mindful of the IXP interconnection hazard these IXPs maintain independence in terms of peering (NAPAfrica, n.d.). In addition to NAPAfrica, South Africa has the Cape Town Internet Exchange (CINX), the Durban Internet
Exchange Point (DINX) and the Johannesburg Internet Exchange Point (JINX). In contrast, local IXPs are much less prevalent along paths between South Africa and other African countries (Gupta et al., 2013), (Fanou et al., 2015). The South African Internet ecosystem bears little resemblance to the rest of the continent in terms of scale, for example, South African IXPs have over 700 connected networks between them whereas the combined peers of all East Africa IXPs is just over 100 (Lodhi et al., 2014), (PeeringDB, n.d.).

RemIX, in the Scottish Highlands, presents an alternative dIXP model for small rural communities. A confederation of small, isolated ISPs connects to a dIXP and together, via the dIXP, members collectively access upstream providers using a single ASN. RemIX node links are agnostic but are typically wireless links in the 2.4 or $5 \mathrm{Ghz}$ bands (Waites et al., 2016). Such a solution could be applied to rural East Africa though for the moment it appears that access is left to the larger MNOs.

Like many developing countries, some East African countries have either no IXP or a single IXP, generally linked to the capital city.

If you grow the local infrastructure,
creating distributed IXPs around the
country. Create a village network
which can actually be rated differently
so for sending email use the village
email server, then I can participate in
the Internet and I am not drawing
down on my data rates if I am just
communicating with the local servers
sitting at the local village post office
"Dickson", Director at an Internet
related organisation)

IXPs are part of the Internet infrastructure ecosystem. I think what we have to do is enhance and build more of it. A country should have at least two or three IXPs. To be specific, one IXP is not enough. ("Robert", Principal Engineer at an ISP)

Some participants described a future where national IXPs develop local IXPs in other cities such that industrial hubs can form and thrive. It is in Government interest to promote a decentralised IXP policy to reduce urban sprawl 
in capital cities. To be successful it is important to understand how such local IXPs achieve transit cost reductions and improved latency times to help the local enterprise and industry without negatively impacting the ISP transit business.

\section{In East Africa we are growing so give it another five years you will actually have enough technical capacity for people to actually manage an IXP in Gulu. ("Denis", Senior government official)}

\begin{abstract}
I think the national IXP needs to put together a system that is going to help build IXPs locally. We need to understand how the cost reduction in terms of international capacity is going to help local businesses reach other local businesses. We need to build infrastructure that is going to help create a better education system for our universities for example. How can we help IXPs grow, as an ecosystem, while partnering with other entities such as the REN or even the private sector? ("Bruno", Network Operations Manager at an ISP)
\end{abstract}

A small number of participants consider that local IXPs are unlikely to happen due to a lack of trained personnel. However, in some ways it has already happened in both Kenya and Tanzania. KIXP has presence in Mombasa and Nairobi, while there are IXPs in Dodoma, Dares-Salaam, Arusha, Mwanza and on the island of Zanzibar off the Tanzanian coast. It is also fair to say that specific circumstances apply in these cases. ISPs converge where the submarine fibre-optic cables land at Mombasa and Dar-esSalaam while Nairobi and Dodoma are capital cities, Zanzibar is semi-autonomous, and Arusha is home to the EAC.

I also don't believe that you will have a situation here where distributed IXPs can be run in remote areas of certain countries any time soon. That has a lot to do with lack of qualified personnel to be able to run these IXPs and that is why I think the IXPs will stay in the main cities. ("Kenneth", Senior Manager at an ISP)
"Lena", an executive board member of a multilateral organisation, cited the case of Brazil which has implemented the world's largest dIXP model across the country. Each IXP in Brazil attracts tier two and three ISPs who provide local Internet access to isolated municipalities currently lacking connectivity. They are attracted by the added benefits including free co-location, a local peering ecosystem and other Internet services associated with a full Network Information Centre (NIC) service that IX.br provides. These additional benefits are not normally associated with IXPs in other counties.
Of course, IXPs in places like Brazil have taken on a whole complete model of a Network Information Centre (NIC) covering everything Internet related, the IXP, the national Internet Registry, etc... ("Lena", Director at an Internet related organisation)

When the survey respondents were asked if in the future there will be the need for the establishment of IXPs in local towns apart from the national capital, strong evidence of homogeneity between groups was demonstrated with only $16 \%$ of respondents in disagreement.

\section{Software-defined disruptive technologies}

The software-defined paradigm that started with servers, then storage, now networks through SDN and with functions through NFV was recognised by many participants as having the potential to really disrupt the evolution of how networks and functions are delivered over the next few years. These are two technologies are having a transformative effect on networking (Goransson et al., 2016) with SDN having already taken hold in IDCs. These applications are supplanting traditional switching and routing technologies. The flexibility offered by SDN and NFV are key ingredients in the delivery of automated cloudbased applications and are central concepts to the design of 5G NR (Lien et al., 2017).

SDN extracts the control functions from networking equipment hardware such that it only handles the data plane functionality (Haleplidis et al., 2015). SDN is a separation of the control and data forwarding functions within the network with control plane functions migrated as software functions to be ran on standard industry hardware, or more 
often than not on server instances located on virtualised cloud platforms.

NFV virtualises services on a hypervisor running on Common Of The Shelf (COTS) hardware. An ISP offering services can replace specialist equipment at the customer site. All services required by customers can then be managed and orchestrated using cloud orchestration tools and new services can be established and torn down remotely. High quality broadband links from the ISPs IDC to the customer premises facilitates the ISP to maximise the benefit of investment by migrating services from physical devices to virtual functions. NFV standardisation is managed under the NFV Industry Specification Group (ISG) within European Telecommunications Standards Institute (ETSI) (ETSI, n.d.).

Since the inception of NFV, both SDN and NFV have been seen to complement each other without necessarily being inter-dependent; however, it is becoming increasingly evident that there is an inter-dependency and new NFV services which link multiple functions that may or may not be located at the same location are being developed that require the flexibility of SDN to chain them. SDN and NFV are considered technologies that will transform network and function management from manual configuration to automation.

[Software-defined is] making it easier to integrate intelligence in centralised management and all kinds of other sophisticated stuff and you can automate it but does that actually create new ways for the networks to interact? ("Assumpta", CEO at an ISP)

Adding intelligence to networks, making them smart, increases efficiency and reduces costs while increasing capability and in time will change how service providers view their place in the market of the future.

The move to software defined means there is a lot more automation, there is a lot less understanding of what goes under the hood because there is a lot more intelligence built into the system and it can automatically make decisions as to how to route traffic. I fear that there are certain skillsets which are likely to be lost and fewer engineers that actually understand. ("Anne", Director at an Internet related organisation)

Today a lot of cost of the Internet is the infrastructure, expensive hardware, expensive back-end infrastructure. NFV, SDN promises to deliver all that with software. Service providers must think more about the applications needed to deliver a type of service wherever we want it, so they [SDN, NFV] have a huge impact on the Internet that way. ("Janet", CTO at an ISP)

Traffic on the Internet has been defined by the users on it. Automation through softwaredefined technologies will make the back-end more efficient but it will not have an impact on user behaviour.

SDN is a fancy way to say having automated Local Area Networks (LAN) and Wide Area Networks (WAN). Traffic has always been pushed by the users and I don't think that will change much. ("Sydney", CEO at an ISP)

SDN and NFV offers operators the ability and flexibility to reduce CAPital EXpenditure (CAPEX) through the employment of COTS hardware instead of expensive function specific hardware. It also allows them leverage open source software projects, such as OpenStack, to focus resources towards tailored services to meet customer needs. They can also reduce OPerational EXpenditure (OPEX) through automation and network intelligence (OpenStack Foundation, 2017).

SDN for operators gives flexibility and bring down the cost of OPEX, it reduces OPEX. The CAPEX may not have that huge impact now because every technology provider is taking huge advantage of the high costs right now. ("Joel", CEO at an ISP)

As the industry and the economic outlook for the region grows, there is increased demand for digital services. ISPs must scale up to meet this demand and software-defined technologies offer an architecture that has the agility to scale with demand. 
To scale up to the demands and requirements of the future generations, there is no other way besides SDN solutions because of the architecture flexibility and the scalability that it brings to us as an operator. The agility that it will bring in terms of how we respond to change in capacity requirement, change in future requirements from the consumers. ("Calvin", CTO at an ISP)

The survey respondents were asked to consider how the trend towards software-defined technologies will shape the Internet of the future. To garner their view the survey asked if SDN is pretty much hype and nothing will change. There was strong evidence of statistical homogeneity, $56 \%$ of the AfNOG group selected strongly disagreed or disagreed with a significant $29 \%$ undecided. A slightly larger $67 \%$ of the ISTA group strongly disagreed or disagreed and again 29\% were undecided. Half of the AfPIF group either strongly disagreed or disagreed with the statement and again 29\% were undecided. The groups were in broad agreement, in fact the AfNOG and AfPIF groups had much the same response while a little over $10 \%$ more of the ISTA group were in disagreement than was seen at the other two groups. This may be reflected in a higher percentage of academics in the ISTA group who may be part of SDN and NFV research groups.

The second survey question asked if NFV is the last throw of the dice for operators, they have lost the application layer battle. The responses demonstrate some confusion among the respondents with over half undecided and practically no respondent having a strong opinion either way. When the three groups are compared there is strong evidence of homogeneity between them with a large undecided vote in each. Considering that respondents are the employees of ISPs (31\%), it is difficult to see NFV assume the future role for which it was originally envisioned. NFV may find a stronger use case as a virtual Customer Edge (vCE) for Global Service Providers (GSP) offering services via partner Local Service Providers (LSP) as well as within the core network of MNO Fifth Generation (5G) New Radio (NR) networks (Weldon, 2015).

\section{The future of the Internet in East Africa}

The evolution of the Internet can be considered in terms of connectivity and infrastructure on one hand, and services on the other. Wired connectivity will see fibre-optic cables get closer to the customer, first to towns with Metro Ethernet style products, then to street cabinets as Fibre To The Kurb (FTTK) and finally into homes via FTTH. Wireless extensions to the fibre-optic tails in the home via $802.11 \mathrm{WiFi}$ to give customers the flexibility and convenience of access will become common as is the case in developed countries. The main wireless technology of the new decade will be 5G NR which is designed to accommodate the nonhuman, Machine to Machine (M2M) communication to Internet of Things (IoT) devices and it is expected that $5 \mathrm{G}$ will in fact have far more M2M devices connected than humans over time. Handsets and other access devices will have increased intelligence for making the switch between available networks based on quality and costs. For example, the handset may use $5 \mathrm{G}$ while in the car on the way home but upon arrival offload to the 802.11 WiFi connected to the FTTH connection, without dropping the data stream or ongoing call.

The connectivity part [of Internet
evolution], you find that there is the
$5 \mathrm{G}$ coming, but obviously the role of
fibre in terms of connectivity is going
to increase because when you talk 5G
you have to do fibre links to each site
to be able to cater for things like IoT.
So, I think the importance of fibre in
all East African countries is
increasing and we see more and more
players probably rolling out FTTH
and fibre to everywhere. ("Calvin",
CTO at an ISP)

The other dimension of the evolution is services. With NFV it is expected that the number and breath of services available to consumers over the Internet will increase and become far more intelligent bringing people, functions, processes, data, and IoT machines together as the Internet of Everything (IoE).

The Internet is enabling lots of new services and we are going to see a lot of IoT and IoE. It will enable services that we have not imagined but will become part of our lifestyle. Things 
like WhatsApp have changed the way we communicate so I am sure there will be a lot more applications that will come and be part of our lives.

("Calvin", CTO at an ISP)

The survey respondents were asked two questions on how they see the future evolution of the Internet in East Africa. Firstly, they were asked to predict the top three technology drivers of the Internet evolution over the next 5 to 10 years in the region. There was strong evidence of statistical homogeneity among the first and second preference choices while the thirdchoice demonstrated weak evidence. This was not surprising considering the number of options presented. There was clear agreement of between $32-39 \%$, among all three groups, that FTTH is the top future technology driver. While AfNOG and AfPIF groups give content caching as their second choice, the ISTA group considered social media and fourth Generation (4G) Long Term Evolution (LTE) as equal second choices.

Respondents were then asked to predict the top three changes that they consider necessary in the ecosystem to facilitate Internet evolution in the region over the next 5 to 10 years. Off continent content dependence was raised as a concern in conversations at many industry conferences in Africa recently and this was highlighted by responses from the three groups demonstrating strong evidence of homogeneity that the creation of local content is the first ecosystem change necessary with selections from $32-39 \%, F T T H$ is given strong prominence too; however, in the case of the ISTA group it is given an equal score with the need for cheaper access devices.

\section{Discussion}

To address the challenge of migration to capital cities it is necessary to build a spatial strategy that develops alternative economic hub towns and cities. Flexible technology industries can be established quickly once the underlying infrastructure is in place. Adequate and robust electrical power, direct high-speed fibre-optic connection links to the submarine fibre-optic landing stations as well as other services such as water, sanitation, road networks and adequate housing are required.
IDCs are also required in the region, so it is heartening to see the Raxio, Uganda's first, open access, carrier neutral, IDC on the outskirts of Kampala join the existing regional open access IDCs such as the ADC Tier III certified IDC in Nairobi, the carrier neutral, icolo Tier III IDCs at Mombasa and Nairobi as well as ADC Kigali expected to open sometime in 2021 (RAXIO, n.d.) (ADC, n.d.) (icolo.io, n.d.). However, these must be just the start and investors should be encouraged to fund the building such key infrastructure nodes within the new hubs and provide stimuli through specialised enterprise organisations, at local level, established and measured to attract and provide the environment necessary for technology businesses to succeed. IDCs provide the platform for technology business to host their server hardware, attracting software businesses to host their platforms on the infrastructure which in turn serves to attract ISPs providing transit services. The IDC is therefore the ideal location for the local IXP to keep local traffic local, which improves each business service offerings.

Inter-governmental organisations such as EACO and the East African Science and Technology Commission (EASTECO) have an important regional role to play advising governments and regulators on the benefits of harmonised Internet infrastructure standards to create a common approach to technology hubs which can support economic growth across the region. A regional strategy, implemented well, has the potential to positively develop all the regional economies, where specialisations in one country can complement specialisations in others making the overall region very attractive to investment.

\section{Conclusion}

Understanding how the Internet developed to this point has more than historical significance. Understanding the triggers that caused the Internet to evolve in the manner that it did, as well as the trajectory of that evolution, can provide industry and academics with learning that can inform future policy development and planning processes. The study also provides insights, from the perspective of industry experts, as to how the future Internet may evolve further. 
It was clear that both the interview participants and survey respondents agreed that the landing of submarine fibre-optic cables was the catalyst to improved Internet experience and infrastructure in the past decade. Both groups also attribute the addition of CDNs by ICPs as well as enhancements to terrestrial fibre and peering to improved streaming video services over the same period.

Survey respondents agree that IXPs have had a positive impact on the Internet in the region. There was some uncertainty as to the next step for IXPs with a future continuing as a point where IXPs and ASPs peer being slightly ahead of the other choices selected. The interview participants were quite clear that IXPs had a positive impact, and the volume of traffic traversing exchange switching fabrics today compared to the past confirms this. They also stated that such growth was due the addition of CDNs directly at IXPs or located at a local ISP with permitted access to it for other ISPs either via the IXP switching fabric or by direct peering.

Most participants in the qualitative interviews and almost $70 \%$ of survey respondents predict a need for IXPs to develop beyond national capitals; however, some were doubtful due to skillset miss matches outside capitals.

On the issue of software-defined technologies many of the qualitative interview participants were sceptical if they would change the nature of the Internet in terms of users and their interaction with it; however, there was broad agreement as to the potential of increased automation and added flexibility to deliver services. There was a note of caution among some that network engineers could lose their understanding of what was happening behind the network and reskilling would be necessary. Some interview participants, close to MNOs, stated that SDN and NFV are integrated within the 5G NR design philosophy.

The survey respondents believe that FTTH, 4G LTE and content cashing are the top three drivers of the future Internet in the region. Interview participants agree that an increase in fibre-optic density linking rural areas and as FTTH deployments in urban centres were key drivers too. The interviewees emphasised that wireless remains the main Internet access method in East Africa and will continue to do so into the future.

Survey respondents consider the creation of local content and the need for government to facilitate infrastructure build, as well as FTTH implementation as priorities to support ecosystem transformation. The interview participants broadly agree and also consider the development of hotspots in villages as well as cheaper smartphone devices as critical issues.

\section{Acknowledgements}

I would like to express considerable appreciation to all the qualitative study interviewees, for their significant contribution to this project. I also wish to thank each and every survey participant for their time and input. A special thanks should be given to the Uganda Communications Commission (UCC) and in particular Helen Nakiguli who were always supportive to this project.

\section{References}

ADC. (n.d.). African Data Centres (ADC). Retrieved 11 May 2020, from https://www.africadatacentres.com

Boyd, C. O. (1993). Combining qualitative and quantitative approaches. NLN Publications, 19-2535, 454-475.

Brito, S. H. B., Santos, M. A. S., Fontes, R. dos R., Perez, D. A. L., Silva, H. D. L. da, \& Rothenberg, C. E. (2016). An Analysis of the Largest National Ecosystem of Public Internet eXchange Points: The Case of Brazil. Journal of Communication and Information Systems, 31(1).

Chatzis, N., Smaragdakis, G., Böttger, J., Krenc, T., \& Feldmann, A. (2013). On the benefits of using a large IXP as an Internet vantage point. Proceedings of the 2013 Conference on Internet Measurement Conference, 333-346.

EACO. (2012a). Report on the taskforce meeting on East African Internet Exchange Points (EAIXPs) connectivity. East African Communications Organisation (EACO). 
EACO. (2012b). The report and proceedings of the 16th congress of the East African Regulatory, Posts and Telecommunications Organisations. East African Regulatory, Posts and Telecommunications Organisations (EARPTO).

EACO. (2014). Report of 3rd meeting of Working Group 5 (WG5)-(IP Networks, Standards and Cybersecurity). EACO.

EACO. (2017). Peering and Interconnectivity in East Africa. East Africa Communications Organisation.

Edwards, R., \& Holland, J. (2013). What is Qualitative Interviewing? Bloomsbury Publishing.

ETSI. (n.d.). Network Functions Virtualisation. Retrieved 1 July 2019, from http://www.etsi.org/technologiesclusters/technologies/nfv

Euro-IX. (n.d.). IXP Database (IXPDB). Retrieved 5 December 2020, from https:/ /ixpdb.euro-ix.net/

Fanou, R., Francois, P., \& Aben, E. (2015). On The Diversity of Interdomain Routing in Africa. Passive and Active Measurement, 41-54.

Flick, U. (2018). An Introduction to Qualitative Research (6th ed.). SAGE Publications.

Fusch, P. I., \& Ness, L. R. (2015). Are we there yet? Data saturation in qualitative research. The Qualitative Report, 20(9), 1408-1416.

Goransson, P., Black, C., \& Culver, T. (2016). Software Defined Networks: A Comprehensive Approach. Morgan Kaufmann.

Graham, M., Andersen, C., \& Mann, L. (2015). Geographical imagination and technological connectivity in East Africa. Transactions of the Institute of British Geographers, 40(3), 334-349.

Gupta, A., Calder, M., Feamster, N., Chetty, M., Calandro, E., \& Katz-Bassett, E. (2013). Peering at the Internet's Frontier: A First Look at ISP Interconnectivity in Africa. 8362, 204-213.

Haleplidis, E., Pentikousis, K., Denazis, S., Salim, J. H., Meyer, D., \& Koufopavlou, O. (2015). Software-defined networking
(SDN): Layers and architecture terminology [RFC]. Internet Engineering Task Force.

Houghton, C., Casey, D., Shaw, D., \& Murphy, K. (2013). Rigour in qualitative casestudy research. Nurse Researcher, 20(4).

Hoyle, R. H. (2018). Improving Health Research on Small Populations: Proceedings of $a$ Workshop. National Academies Press.

icolo.io. (n.d.). Icolo.io. Icolo.Io. Retrieved 12 March 2020, from https://www.icolo.io

INEX. (n.d.). INEX traffic analysis [INEX MRTG Statistics]. https://www.inex.ie/Technical/Stats.

Krejcie, R. V., \& Morgan, D. W. (1970). Determining sample size for research activities. Educational and Psychological Measurement, 30(3), 607-610.

Leininger, M. (1994). Evaluation criteria and critique of qualitative research studies. Critical Issues in Qualitative Research Methods, 95, 115.

Lien, S.-Y., Shieh, S.-L., Huang, Y., Su, B., Hsu, Y.-L., \& Wei, H.-Y. (2017). 5G new radio: Waveform, frame structure, multiple access, and initial access. IEEE Communications Magazine, 55(6), 64-71.

Lodhi, A., Larson, N., Dhamdhere, A., Dovrolis, C., \& Claffy, K. (2014). Using PeeringDB to Understand the Peering Ecosystem.

McCann, M. (2018). Teraco: An African story. The journey of a vendor neutral data centre. AfPIF 2018, Capetown, South Africa.

Muttitanon, W., \& Samanchuen, T. (2020). Internet Cost Reduction Using Internet Exchange Point: A Case Study of Internet Network of Thailand. Wireless Personal Communications, 1-22.

NAPAfrica. (n.d.). NAPAfrica. Retrieved 2 July 2019, from https:/ / www.napafrica.net

Norton, W. B. (2014). The Internet Peering Playbook: Connecting to the Core of the Internet. DrPeering Press.

OpenStack Foundation. (2017). OpenStack Ocata Strengthens Core Infrastructure Services and Container Integration with 15th Release of Cloud Computing Software. 
Peering, D. B. (n.d.). Peering D. B. Retrieved 12 August 2018, from https://www.peeringdb.com

RAXIO. (n.d.). Uganda's first Enterprise Grade Data Centre. Retrieved 11 May 2020, from https://www.raxio.co.ug

Shi, Q., Wang, X., \& Lin, W. (2018). Placement Strategy for Replicated Servers in CDN. 2018 37th Chinese Control Conference (CCC), 6410-6416.

UIXP. (n.d.). UIXP traffic analysis. Retrieved 12 June 2019, from http://stats.uixp.co.ug/mrtg/
Waites, W., Sweet, J., Baig, R., Buneman, P., Fayed, M., Hughes, G., Fourman, M., \& Simmons, R. (2016). Remix: A distributed internet exchange for remote and rural networks. Proceedings of the 2016 Workshop on Global Access to the Internet for All, 25-30.

WEF. (2018). Internet for All: Financing a Forward-Looking Internet for All. World Economic Forum.

Weldon, M. K. (2015). The Future X Network: A Bell Labs Perspective. CRC Press INC. 